\title{
How Real Managers In The Real World Build Real Teams: A Call For Relevance
}

David L. Mathison, (Email: dmathiso@lmu.edu), Loyola Marymount University

\begin{abstract}
Few places in the management literature is there a greater divide between theory and practice than in Team Building. Yes, academics have thoroughly researched what this "ideal team" should look like, its various developmental stages, even the proper mix of roles - yet this author would argue we as educators and consultants know little of how to really develop teams and offer even less of this in equipping our students-managers for this central task. The purpose of this paper is a call for relevance - a challenge to move from speculative theory on team development to actual practice - identifying what works and what doesn't. Following a literature review which underlines how theoretical our field has become concerning team development, an actual research study will be reported. Forty-two MBA students participated in a study where near ideal work teams were developed. Then these same students were asked, "What went right? Identify four lessons you learned on how to build an energized team." The following is a partial list of student observations on what contributed most to an ideal team: listening, clearly defined goals and tasks, respect for each other, urgency of time, strong norms that rejected loafers, lack of formal structure, and allowing natural leaders to lead.
\end{abstract}

The paper ends with a discussion on implications for managers hoping to develop energized work teams:

- $\quad$ Ad Hoc Teams are Best. Standing groups which lack "Sunset Causes" tend to become political over time.

- $\quad$ Find the Right Mix between Formal and Informal. Informal gives energy, formal gives needed structure.

- $\quad$ Leadership Must Emerge Early in the Process and be Accepted by Most. There is a critical moment where leaderless teams dissolve into political games.

- $\quad$ Strong Norms of Mutual Respect Must be Present from the Beginning. The tendency toward competition in early team formation must quickly be moderated and directed toward task completion.

In conclusion, our theoretical traditions have led us to a profound understanding of group dynamics, but to remain relevant we owe our students a practical guide as well. A guide that discussed how Real Managers in the Real World develop Real Teams.

\section{Inttroduction}

$f$

ew places in the management literature is there a greater divide between theory and practice than in Team Building. Yes, Academics have thoroughly researched what this "ideal team" should look like, its various developmental stages, even the proper mix of rules - yet this author would argue we as educators and consultants know little of how to really develop teams and offer even less of this in equipping our students-managers for this central task.

The purpose of this paper is a call for relevance, a challenge to move from speculative theory on team development to actual practice - identifying what works and what doesn't. Following a literature review which 
underlines how theoretical our field has become concerning team development, an actual research study will be reported. Finally implications will be discussed and compared with some recent popular publications that are now beginning to address directly the concern in this paper - "How Real Managers Build Real Teams".

\section{Are Even the Team Consultants Too Theoretical?}

In an effort to locate information that attempted to transcend theory on team building such as McGregor's "well functioning team" (1960) and offer practical guidelines, the author conducted an internet search for information supplied by consultant groups. The results were disappointing.

One group, "Team Technology" (www.teamtechnology.couk) discussed at length group pathologies, including the "Apollo Syndrome" where collective performance falls short of the team's best performer. The site went on to discuss both goals and how individual types of teams (i.e., sales, administrators, cleaning staffs) should function differently. This group concluded with what they identified as the three natural stages of team development: 1) clarify team goals, 2) identify issues that inhibit these goals, and 3) removing inhibitors and enabling goals to be achieved. All likely valuable information on how teams should function but little help on how to accel-team (www.accel-team.com). Another consulting group hinted at practical help. Yet in their published article, "How to Lead Informal Work Groups," little practical information was provided. Later they noted, "An understanding of informal workgroups is a must!" The site then proceeded with pages of models.

The consulting group "Team Management Systems" (www.tms.com.au/tms) teased the reader of this site with an article titled "Transforming Groups into Teams", but then went on with their list of an ideal teams citing only well known objectives as common goals and objectives, harnessing diversity and fostering effective communication. A second aid provided was the "work wheel", a rehash of Tuchman's (1960) work where group roles were identified such as advising, maintaining, promoting, and so on. Again little practical help.

Another consulting site visited was "Paradox UK Team Building Research (www.paradoxuk.com/ research.htm). This site simply defined the "team" and developed a list of "factors affecting team development".

The final site made the greatest promise with an article titled "Developing a Productive Team". This group, "Nebraska Cooperative" (www.ianr.unl.edu), again proved disappointing. They only provided lists of "ideal conditions for teams," (Francis and Young, 1979) and their own version of "characteristics of a focused team". Again the focus was only outcomes, not process, by example, "team member should have a positive attitude toward change".

Certainly this review is not exhaustive. As well the rewards for most consultant groups do not lie in revealing solutions to effective team building on-line, yet the author and possibly potential clients are left wondering do they really have any more "tricks in their bag". As said earlier in this paper, there is a vast difference between citing characteristics of an ideal team and actually facilitating an effective team as a practicing manager.

\section{A Real Example of How Real Managers Built Real Teams}

\section{The Assignment}

The author conducted an interesting informal experiment in his MBA Advanced Communication class. Team building was only briefly discussed in class by reviewing McGregor's Eight Characteristics of An Ideal Team (1960). This individual class had 27 students and for a final in-class project, they were assigned the task of assessing both the dynamics of a highly dysfunctional small company and developing practical solutions. Furthermore, this organizational development-style assignment was to be completed along with a well-written document of 25 pages due in the span of no more than seven days. To add to the difficulty of the assignment, students in this evening class lived as far apart as 100 miles and were only given $1 \nabla$ hours of class time to achieve it. The class was divided randomly in half and each group both role-played a dysfunctional company and roleplayed an organizational development consulting team. 


\section{The Surprising Accidental Outcome}

While the "Consultant Report" for both teams proved an excellent document, the most remarkable aspect of this one-week project was the profound (word used carefully) strength of each of the two teams. The Author, carefully and unobtrusively monitored both teams' development, including how leadership emerged, how conflicts were managed, how tasks were assigned, how communication developed, and so on. With breathtaking consistency each of the ad hoc teams accurately displayed all eight dimensions of a well functioning group as originally described by Doug McGregor in The Human Side of the Enterprise (1960):

- $\quad$ Atmosphere tends to be relaxed, comfortable and informal.

- $\quad$ Groups task is well understood and accepted by the members.

- $\quad$ Members listen well to each other; there's a lot of task-relevant discussion which most participate.

- $\quad$ People express both feelings and ideas.

- $\quad$ Conflict and disagreement are present, but centered on ideas and methods, not personalities.

- $\quad$ Group is self conscious about its own operation.

- $\quad$ Decisions are usually based on consensus, not majority rule.

- Finally, when actions are decided upon, clear assignments are made and accepted by the members.

\section{The Experiment}

One week following the project, this writer included a two-page essay question as part of the Final Exam. The question read as follows:

"In class you were a member of a team that functioned remarkable similar to McGregor's Energized Team. Identify four lessons in team building you have learned from this experience that you may wish to apply as a practicing manager. (Please do not describe your team - rather explain lessons learned on how to build an energized team.)

The purpose of this question was not research - rather desire that the students to begin to learn from experience to actually identify "what when right" so they can apply these lessons in management. They were asked to do very practical analysis of their own successful experience apart from textbook learning.

\section{The Findings}

The student provided brief but thoughtful answers. The following is a partial list of random observations: six students said "we listened," others, "other comments included our norms: didn't allow slackers, we respected each other, there were clear assignments, we had open communication, we worked as equals, we didn't want to let the others down, we broke a large task into small assignments, the quick deadline helped, we let the natural leader lead, we ridded all formalities - no rules, no bosses, there was a sense of urgency, we harnessed conflict, we worked toward consensus always."

Completing a "Content Analysis", the writer summarized along with the writer's observations, these verbatim responses into the following clusters:

- Ad Hoc Teams are Best standing groups, which lack "Sunset causes tend to become political over time".

- $\quad$ Find the Right Mix between Formal and Informal. Informal gives energy; formal gives needed structure.

- $\quad$ Leadership Must Emerge Early in the Process and be Accepted by Most. There is a critical moment where leaderless teams dissolve into political games.

- $\quad$ Strong Norms of Mutual Respect Must be Present from the Beginning. The tendency toward competition in early team formation must quickly be moderated and directed toward task completion, and a critical part of respect is to listen, listen, and listen some more. 
Implications: A Ray of Hope in the Popular Literature

If the academic and consulting publications are excessively focused on the theoretical, there is emerging in the popular literature sage insights into the practical realm of team building. And what's echoed by these MBA students is also reflected in many of these refreshingly new publications.

By example, in Joan Magretta's landmark book, What Management Is (2002), she makes the case that the corporation is an interlink of an economic machine and social systems, and to succeed as a manager, both aspects must be mastered. But unlike other publications, she moves beyond "what" to "how." In detail and with countless practical examples, Magretta coaches the reader how to build culture, develop trust - her manager's "Golden Rule." She also makes a passionate case for respect for the individual and explains in significant detail how this is done and not done using again very clear examples.

Likewise David Goleman's new book, Primal Leadership (2002), offers invaluable practical guidance to Team Building - using "Emotional Intelligence" as the foundation. Beginning with his four fold mantra: self awareness, self management, social awareness and relationship management he explores in profound detail not only the "what" but also like Magretta, the "hows". Goleman parroting the writers MBA students see developing the "empathic team" as the heart of the matter along with uncovering for the team how they see themselves, their "emotional reality." But unlike so many academic works on team building, Primal Leadership provides detail case and clear suggestions on how this is accomplished.

\section{Conclusion}

In 1997 Peter Drucker made a dire prediction about the usefulness of management education and academic research, "Thirty years from now, the big university campuses will be relics. Universities won't survive." (Drucker, 1997). In this statement, Drucker was addressing, in part, the vast chasm between theory and actual practice.

This author would second Drucker's judgment with regard to team building. If even the consultants' writing is a parade of paradigms, theories, and ideals, how much more impractical is cold research on the same topic?

It seems at times the student know more than the master.

\section{References}

1. Accel-team (www.accel-team.com).

2. Drucker, P. (1997), "Seeing Things as They Really Are," Forbes, 159 (5), 122-128.

3. Francis, D. and Young, D., (1979), Improving Work Groups: A Practical Manual for Team Building, University Associates, San Diego.

4. Goleman, D., Boyatzis, R., and McKee, A., (2002), Primal Leadership, Boston, Harvard Business School.

5. Magretta, J., (2002), What Management Is, New York, Free Press.

6. Margerison-McCann, Team Management Systems (www.tms.com).

7. McGregor, D., (1960), The Human Side of Enterprise, New York, McGraw.

8. Nebraska Cooperative (www.ianr.unl.edu).

9. Paradox UK Team Building (www.paradoxuk/research.htm).

10. Team Technology (www.teamtechnology.couk).

11. Tuchman, B., (1965), "Development Sequence in Small Groups," Psychological Bulletin, 63 (6). 